\title{
SIMULATING THE EFFECT OF LEARNING DECAY ON ADAPTATION PERFORMANCE IN PROJECT NETWORKS
}

\author{
Jiayu Chen \\ John E.Taylor \\ Hakan I.Unsal \\ 618 S.W. Mudd Building \\ 500 West $120^{\text {th }}$ Street \\ Dept. of Civil Engineering and Engineering Mechanics \\ Columbia University \\ New York, NY, 10027, USA
}

\begin{abstract}
In this paper we extend a multi-agent simulation model for interorganizational learning to explore the issue of learning decay on adaptation performance. Researchers agree that project networks can support the development and exchange of new knowledge among firms, however, the question of learning beyond the firm at the boundaries between firms or at the level of the network remains less explored. Previous research has shown that relational instability in networks can slow learning and that task interdependence moderates the impact of increasing relational instability on project network adaptation performance. Research to date on this phenomenon neglects the effect of forgetting which may impact the performance of project networks where firms work together infrequently. We find these gaps in time between learning events can negatively impact the adaptation rate of relationally unstable project networks. These findings are critical to developing a comprehensive understanding of learning in interorganizational project networks.
\end{abstract}

\section{INTRODUCTION}

Developing a comprehensive understanding of the learning process is critically important to determining project schedule and, hence, to estimate cost. Scholars studying learning at the level of the project network have examined knowledge extensively in the cross-organizational context examining how knowledge flows (Appleyard 1996), transfers (Mowery et al. 1996), spills over (Uzzi and Gillespie 2002), and diffuses (Zucker et al. 1996). Understanding learning at the level of the project network is particularly important in architecture, engineering and construction projects where a large number of task interdependent firms assemble to execute a project. However, learning decay, or forgetting, and its impact on learning in project networks has not been examined.

In the architecture, engineering and construction industry, cooperation between the general contractor, subcontractors, the numerous engineering consultants, and the architects, among other firms, are diverse and relationships among them do not necessarily carry forward from one project to the next project. When a project network must adapt to a systemic innovation (i.e., an innovation that impacts more than one type of firm in the network (Taylor and Levitt 2004)), the network's ability to adapt to such change is critical. Adaptation performance of a network is an important parameter to the efficient functioning of a project network and the overall productivity performance of the industry. When adapting to the systemic changes, the forgetting that can occur in gaps of time between learning events among firms may impact adaptation performance. In this paper we developed a multi-agent simulation model to explore the effect of learning decay on performance in relationally unstable project networks.

\section{BACKGROUND}

\subsection{Learning and Forgetting Functions}

Learning is acquiring new knowledge, behaviors, skills, values, preferences or understanding, and may involve synthesizing different types of information and its process follows learning curve, which can represent the initial difficulty of learning something and, to an extent, how much there is to learn after initial familiarity. The ability to learn is possessed not only by 


\section{Chen, Taylor and Unsal}

humans but also by organizations. Forgetting (retention loss) refers to apparent loss of information already encoded and stored in an individual or organization's long term memory. It is a spontaneous or gradual process in which old memories are unable to be recalled from memory storage. Forgetting can reduce the productivity of industrial production due to loss of familiarity, experience and memory.

Research on learning and forgetting has both industrial and psychological origins. A critical early finding in this research was the discovery that the determinant of forgetting is the original level of learning achieved (Underwood 1968, Wickelgren 1981, Christiaansen 1980, Carron 1971). This theoretical argument was later proven in laboratory studies by Charles D. Bailey (1989). Bailey's experiment found the relearning rate is not correlated with the learning rate but with the degree of original learning. Carlson and Rowe (1976) developed a learn-forget-learn (LFL) analysis procedure to calculate the loss of forgetting. Based on these conclusions, Jaber and Bonney (1997) compared three different forgetting models variable regression to invariant forgetting (VRIF), variable regression to variable forgetting (VRVF) and learn-forgetting curve model (LFCM), to identify the best formula of the forgetting function. They found the power function introduced by Wixed and Ebbesen (1991) as the most accurate forgetting model. Research to date has considered forgetting within organizations; however, to date forgetting models have not been applied in the context of interorganizational project network learning. Since firms in project networks are required to adapt to many localized and systemic changes in the network (Taylor and Levitt 2004) and since the coupling of firms in project networks may be marked by periods of relational instability (Taylor and Levitt 2007), forgetting may play an important role in project network adaptation processes.

\subsection{Project Networks}

Rooted in the Coase's (1973) and Williamson's (1975) theory of markets and hierarchies, Eccles (1981) proposed the existence of quasi-firm interorganizational networks after studying firm coupling in the Massachusetts construction industry. Eccles found the relationship between the contractor and subcontractor to be relatively stable. However, more recent research on project networks finds these interorganizational networks, particularly in the United States, to be relatively relationally unstable (Taylor and Levitt 2007). Powell (1998) argues that innovation may be stifled in relationally unstable networks. Taylor and colleagues (in press) later described how task interdependence and relational instability can negatively impact adaptation performance. We lack research that considers the impact relational instability may have on forgetting in the project network.

\subsection{Learning Dynamics Simulation in Architecture, Engineering and Construction}

Computational modeling of learning is not uncommon in investigations of the architecture, engineering and construction industry, especially when discussing the relation between the design and construction. Researchers have modeled knowledge generation (Soibelman and Kim 2002), corporate memory design reuse systems (Demian and Fruchter 2006), and collaborative learning processes in architecture, engineering and construction teams (Fruchter1999, Hussein and Pena-Mora 1999). Hijazi, AbouRizk and Halpin (1992) and Lutz, Halpin and Wilson (1994) developed simulation models to predict the learning of individuals working in construction. This research focused on the impact of learning on productivity within organizations. A more recent study investigates the dynamics of knowledge flows using computational simulation across organizations in construction networks (Ibrahim \& Nissen 2003). This investigation developed interesting scenarios for the flow of knowledge across organizational boundaries, but did not consider learning that would have necessarily followed such exchanges and impacted productivity rates as the project network adapted to change.

More recently, researchers have developed simulation models to investigate the learning between task interdependent organizations on a project (Taylor, Levitt and Villarroel in press, Unsal and Taylor 2009, Villarroel and Taylor 2006). This research was based on an earlier empirical study in which interorganizational boundary spanning technological changes induced a set of interorganizational change variables (Taylor and Levitt 2007). These variables were later refined into a baseline computational simulation model to evaluate project network dynamics. The project network dynamics simulation research demonstrates that relational instability in a project network slows learning and that task interdependence moderates the impact of increasing relational instability on network productivity rates. However this reduction in productivity does not take forgetting into account, which may be a significant factor in unstable networks. This paper extends previous simulation research on unstable network learning to incorporate the learning decay that occurs in the gaps in time between the couplings of firms in the network. 
PROJECT NETWORK DYNAMICS ADAPTATION PERFORMANCE MODEL

\subsection{The baseline project network dynamics model}

The baseline model borrows from the general form of the learning curve described in Wright (1936). In a stable participation environment, firms from different roles work together for relatively long periods of time and have a steady adaptation rate. In such situations, the individual and firm productivity should follow the classical learning curve identified by Wright (1936). Under this assumption, given a firm $i$, its individual productivity is

Where;

$$
\Pi_{\mathrm{i}}=\Pi_{0} \cdot\left(\mathrm{n}_{\mathrm{i}}\right)^{\mathrm{L}_{\mathrm{i}}}
$$

$\Pi_{\mathrm{i}}=$ productivity factor for the firm i

$\Pi_{0}=$ initial productivity factor for individual work

$\mathrm{n}_{\mathrm{i}}=$ number of individual tasks executed by firm $\mathrm{i}$

$\mathrm{L}_{\mathrm{i}}=\log _{2} \lambda_{\mathrm{i}}=$ characteristic learning index for firm $\mathrm{i}$

$\lambda_{\mathrm{i}}=$ learning rate

The learning rate for construction networks is generally in the range from 0.7 to 0.9 (Oglesby et al. 1988). In the simulation we use 0.8 as an average industry learning rate value in the simulation. The model consists of a total of $\mathrm{N}$ firms $\{1, \ldots, \mathrm{i}, \ldots, \mathrm{N}\}$ and a given firm implements a specialized role $\mathrm{R}_{\mathrm{i}}$. Several firms may belong to the same role, and there are a total of $M$ roles $\left\{R_{i}, R_{j}, \ldots, R_{M}\right\}$.

The actual execution time is given by:

$$
\mathrm{T}_{\mathrm{i}}=\Pi_{\mathrm{i}} \cdot \mathrm{T}_{\mathrm{Ri}}
$$

In addition, between firms there may be task interdependent interorganizational learning. Taking 2 firms $(\mathrm{i}, \mathrm{j})$ as an example, we consider the network learning as existing between every two firms and the degree of task interdependence which is $\mathrm{X}_{\mathrm{ij}}$.

$$
\Pi_{\mathrm{ij}}=\Pi_{00} \cdot\left(\mathrm{n}_{\mathrm{ij}}\right)^{\mathrm{L}_{\mathrm{ij}}}
$$

Where;

$\Pi_{\mathrm{ij}}=$ productivity factor for the collaborating firm $\mathrm{i}, \mathrm{j}$

$\Pi_{00}=$ initial productivity factor for collaborative work

$\mathrm{n}_{\mathrm{ij}}=$ number of individual tasks executed by firm $\mathrm{i}, \mathrm{j}$

$\mathrm{L}_{\mathrm{ij}}=\log _{2} \lambda_{\mathrm{ij}}=$ learning index between firm $\mathrm{i}, \mathrm{j}$

$\lambda_{\mathrm{ij}}=$ learning rate between firm $\mathrm{i}, \mathrm{j}$

$\mathrm{T}_{\mathrm{Ri}}=$ characteristic time for the execution of the first independent task by firm i in role Ri

Similar to the single firm case, given a level of collaborative interdependent work for the firm dyad (i, $j$ ), defined as a percentage of firm i's characteristic execution time $\mathrm{T}_{\mathrm{Ri}}$, the actual one-sided execution time of this collaborative portion of the work is given by:

Where;

$$
\mathrm{T}_{\mathrm{ij}}=\Pi_{\mathrm{ij}} \cdot \mathrm{X}_{\mathrm{ij}} \cdot \mathrm{T}_{\mathrm{Ri}}
$$

$\mathrm{X}_{\mathrm{ij}}=$ Degree of Task Interdependence

\subsection{Integrating the Forgetting Curve Model}

Participation of firms in a project network may be unstable requiring some firms not to work together for extended periods of time. This means that if a firm is not selected to be part of the project network, they will experience a period over which memory decay - or forgetting- will occur. We adopt the forgetting curve model established by Carlson and Rowe (1976):

$$
\widehat{\mathrm{T}}_{\mathrm{x}}=\widehat{\mathrm{T}}_{1} \mathrm{x}^{\mathrm{f}}
$$

Where;

$\widehat{\mathrm{T}}_{\mathrm{x}}=$ the time for the $\mathrm{xth}$ project of lost experience of the forgetting curve

$\widehat{T}_{1}=$ the equivalent time for the initial project of the forgetting curve

$\mathrm{f}=$ the forgetting rate

$\mathrm{x}=$ the number of project that experienced forget 
As indicated in the research of Jaber and Bonney (1996), forgetting is a function of the learning curve. Based on their study we select the most realistic forgetting model LFCM, which uses an unfixed forgetting slope as our start point, and combine Hovland (1951)'s suggestion to take performance at the time and the length of the interruption as the two key variables. Figure 1 illustrates the form of the forgetting curve over time. In the figure, $\mathrm{tB}$ is the minimum time for total forgetting, tp is the time to finish $\mathrm{n}$ projects, tb is the time break experienced in a forgetting period.

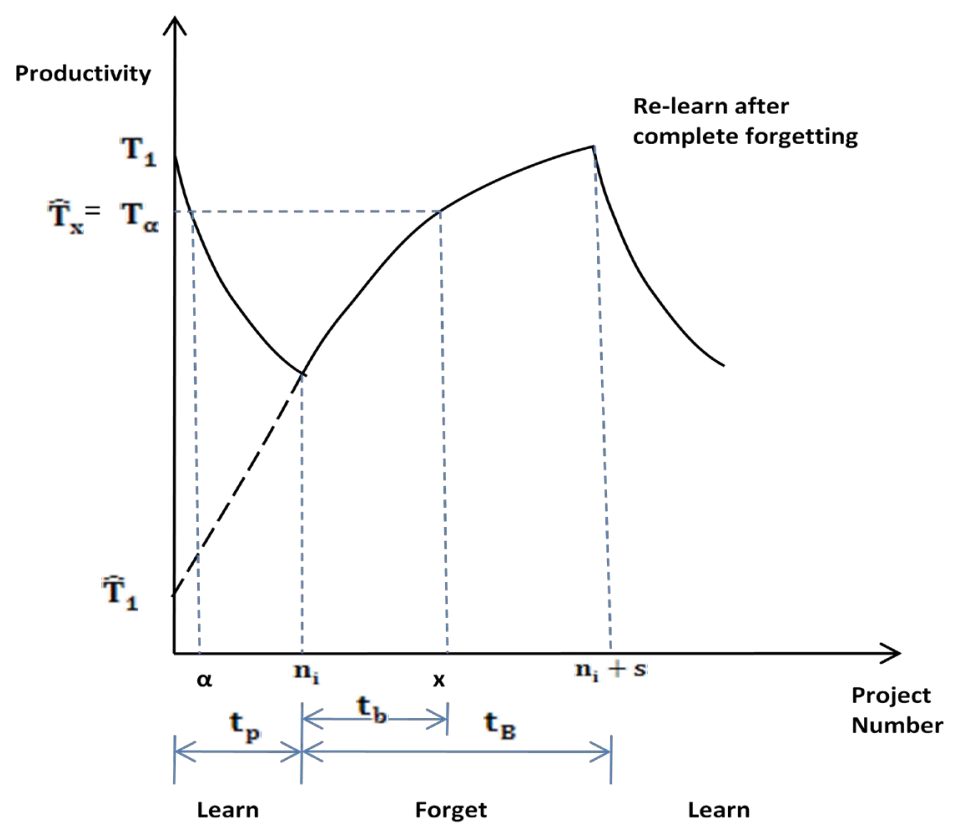

Figure 1: Learning Curve with a Period of Forgetting

From (1) and (2), we model the first interruption which creates a period of forgetting as follows,

Therefore,

$$
\begin{gathered}
\mathrm{T}_{\mathrm{i}}=\Pi_{\mathrm{i}} \cdot \mathrm{T}_{\mathrm{Ri}} \\
\Pi_{0} \cdot\left(\mathrm{n}_{\mathrm{i}}\right)^{\mathrm{L}_{\mathrm{i}}} \cdot \mathrm{T}_{\mathrm{Ri}}=\widehat{\Pi}_{\mathrm{i}} \cdot\left(\mathrm{n}_{\mathrm{i}}\right)^{\mathrm{f}} \cdot \mathrm{T}_{\mathrm{Ri}}
\end{gathered}
$$

Solving for the forgetting rate $\mathrm{f}$, we find:

$$
\mathrm{T}_{\mathrm{i}}=\Pi_{0} \cdot\left(\mathrm{n}_{\mathrm{i}}\right)^{\left(\mathrm{L}_{\mathrm{i}}-\mathrm{f}\right)} \cdot\left(\mathrm{n}_{\mathrm{i}}+\mathrm{S}\right)^{\mathrm{f}} \cdot \mathrm{T}_{\mathrm{Ri}}
$$

We can then calculate the total forgetting time break $t_{\mathrm{B}}$ :

$$
f=L_{i} \frac{\log n_{i}}{\log n_{i}-\log \left(n_{i}+S\right)}
$$

$$
\mathrm{t}_{\mathrm{B}}=\sum_{\mathrm{n}_{\mathrm{i}}}^{\mathrm{n}_{\mathrm{i}}+\mathrm{S}} \Pi_{0} \cdot \mathrm{T}_{\mathrm{Ri}} \cdot\left(\mathrm{n}_{\mathrm{i}}\right)^{\mathrm{L}_{\mathrm{i}}}=\frac{\Pi_{0} \cdot \mathrm{T}_{\mathrm{Ri}}}{1+\mathrm{L}_{\mathrm{i}}}\left[\left(\mathrm{n}_{\mathrm{i}}+\mathrm{S}\right)^{1+\mathrm{L}_{\mathrm{i}}}-\left(\mathrm{n}_{\mathrm{i}}\right)^{1+\mathrm{L}_{\mathrm{i}}}\right]
$$

The cumulative time experienced forgetting is then:

And

$$
t_{p}=\frac{\Pi_{0} \cdot T_{R i}}{1+L_{i}}\left(n_{i}\right)^{1+L_{i}}
$$

Finally we can calculate the local forgetting rate $\mathrm{f}$ :

$$
\begin{gathered}
\left(n_{i}+S\right)=\left[\frac{1+L_{i}}{\prod_{0} \cdot T_{R i}} t_{B}+\left(n_{i}\right)^{1+L_{i}}\right]^{1 / 1+L_{i}} \\
\left(n_{i}+S\right)=n_{i}[C+1]^{1 / 1+L_{i}}
\end{gathered}
$$

$$
f=\frac{-L_{i} \cdot\left(1+L_{i}\right) \log n_{i}}{\log (C+1)} \text {, where } C=t_{B} / t_{p}
$$

Referring back to Figure 1, ni represents the project number at which forgetting begins, $\mathrm{s}$ is the interruption period in dimension of project, $\alpha$ is the equivalent project number at the beginning of next learning process after a period of interruption, and $\alpha$ can be calculated as follows: 


$$
\alpha=\left(n_{i}\right)^{\frac{L_{i}-f}{L_{i}}}\left(n_{i}+S\right)^{\frac{f}{L_{i}}}
$$

Therefore, the time to finish the first project after a forgetting period is

$$
\widetilde{T}_{i+1}=\Pi_{0} \cdot T_{R i}\left[\left(n_{i}\right)^{\frac{L_{i}-f}{L_{i}}}\left(n_{i}+S\right)^{\frac{f}{L_{i}}}\right]^{L_{i}}
$$

\subsection{Normalization of the Simulation Results for Comparison}

The total execution time for the project of the network is $T_{P}$, which is the sum of all independent tasks executed by each individual firm. This is,

$$
\mathrm{T}_{\mathrm{P}}=\sum_{\mathrm{i}}^{\mathrm{M}} \mathrm{T}_{\mathrm{i}}+\sum_{\mathrm{i}}^{\mathrm{M}} \sum_{\mathrm{j} \neq \mathrm{i}}^{\mathrm{M}} \mathrm{T}_{\mathrm{ij}}, \forall \mathrm{i}, \mathrm{j} \in \mathrm{P}
$$

In order to plot and compare the performance of the different models, we perform a normalization function, and the normalizing factor is:

$$
\mathrm{T}_{\mathrm{N}}=\sum_{\mathrm{i}}^{\mathrm{M}} \mathrm{T}_{\mathrm{Ri}}+\sum_{\mathrm{i}}^{\mathrm{M}} \sum_{\mathrm{j} \neq \mathrm{i}}^{\mathrm{M}} \mathrm{X}_{\mathrm{ij}} \mathrm{T}_{\mathrm{Ri}}
$$

Therefore, the normalized performance of any given project is given by:

$$
\overline{\mathrm{T}_{\mathrm{P}}}=\frac{\mathrm{T}_{\mathrm{P}}}{\mathrm{T}_{\mathrm{N}}}
$$

\section{SIMULATION EXPERIMENTAL DESIGN AND RESULTS}

When considering the impact of forgetting on a project network, we are specifically interested in finding out whether the adaptation rate is impacted by the forgetting period. Figure 2 contains a comparison of the individual firm learning without considering forgetting (top graph) and with forgetting included (bottom graph). Without forgetting, when there is no project assigned to a firm, the firm will stop learning and the productivity will remain the same value. For example, in Figure 2 in the period from project 9 to project 14, the productivity of the network is unchanged during this period when the firm is not participating in a project network. However, in the model of learning with forgetting the productivity worsens during the period of forgetting, negatively impacting the adaptation rate. In the same period from project 9 through 14 we observe the productivity values worsening due to forgetting.

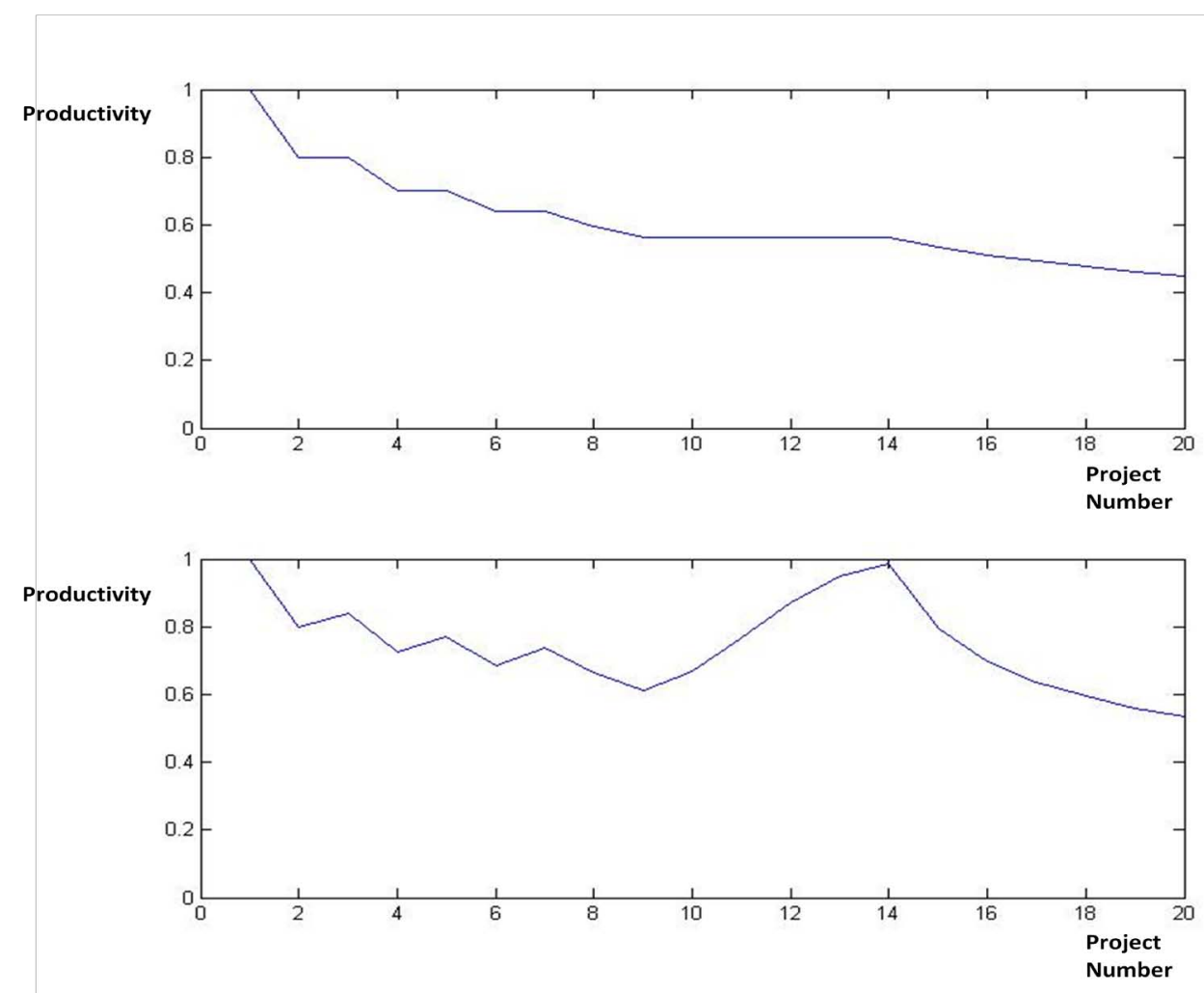

Figure 2: Individual Firm Adaptation Performance Without Forgetting (upper graph) and With Forgetting (lower graph) 


\subsection{The Impact of Forgetting}

To examine the impact of forgetting more fully, we designed an experiment to examine scenarios with varying relational instability values. We test networks for which there is only one firm per role through the more relationally unstable case where there are four firms that can fulfill each specialist role in the network. Additionally, for each we executed a single simulation and calculated the average of 10,000 simulation runs. We executed the same experimental design with forgetting and without forgetting. Table 1 contains the input parameters of the simulation experiment.

Table 1: Simulation Experiment to Compare Project Network Productivity with and without Forgetting

\begin{tabular}{|c|c|c|c|c|c|c|c|}
\hline $\begin{array}{l}\text { \# Firms per } \\
\text { Role }\end{array}$ & $\begin{array}{l}\text { Degree of Task } \\
\text { Interdependence }\end{array}$ & $\begin{array}{c}\text { Learning } \\
\text { Rate }\end{array}$ & $\begin{array}{l}\text { \# Projects } \\
\text { Simulated }\end{array}$ & $\begin{array}{l}\text { Project } \\
\text { Duration } \\
\text { (days) }\end{array}$ & $\begin{array}{c}\text { Total } \\
\text { Forgetting } \\
\text { Time (days) }\end{array}$ & $\begin{array}{c}\# \\
\text { Simulations } \\
\text { Run } \\
\end{array}$ & $\begin{array}{l}\text { Figure } \\
\text { Number }\end{array}$ \\
\hline $\begin{array}{c}1 \text { firm per } \\
\text { role }\end{array}$ & \multirow{4}{*}{0.5} & \multirow{4}{*}{0.8} & \multirow{4}{*}{20} & \multirow{4}{*}{100} & \multirow{4}{*}{1,000} & $\begin{array}{c}1 \\
10,000\end{array}$ & $\begin{array}{l}\text { Figure 3-1 } \\
\text { Figure 3-2 } \\
\end{array}$ \\
\hline $\begin{array}{l}2 \text { firms per } \\
\text { role }\end{array}$ & & & & & & $\frac{1}{10,000}$ & $\begin{array}{l}\text { Figure 3-3 } \\
\text { Figure 3-4 }\end{array}$ \\
\hline $\begin{array}{l}3 \text { firms per } \\
\text { role }\end{array}$ & & & & & & $\frac{1}{10,000}$ & $\begin{array}{l}\text { Figure 4-1 } \\
\text { Figure 4-2 }\end{array}$ \\
\hline $\begin{array}{l}4 \text { firms per } \\
\text { role }\end{array}$ & & & & & & $\frac{1}{10,000}$ & $\begin{array}{l}\text { Figure 4-3 } \\
\text { Figure 4-4 }\end{array}$ \\
\hline
\end{tabular}
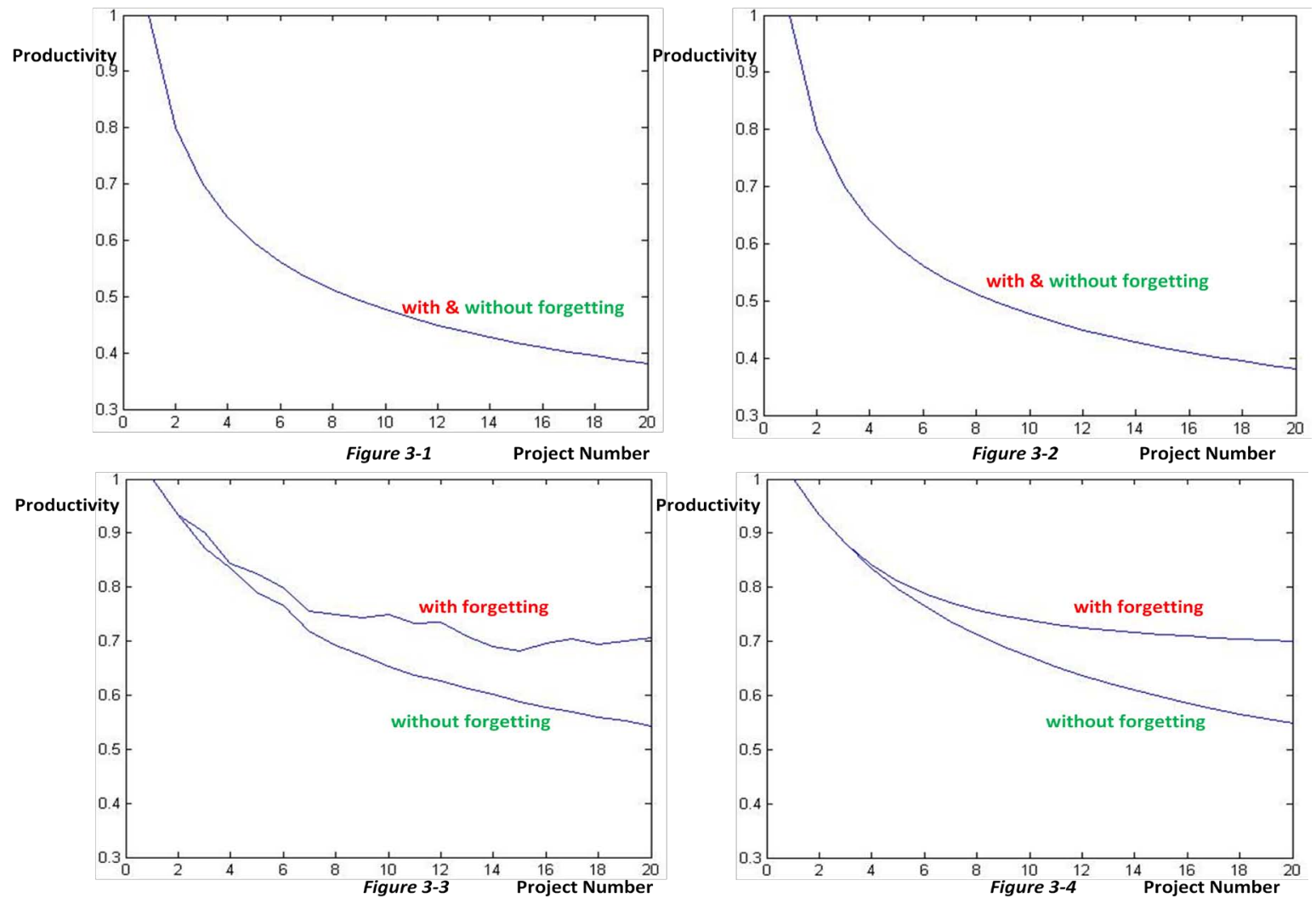

Figure 3: Comparisons of Adaptation Performance With and Without Forgetting with Varying Relational Stability (Figure 31 and 3-3: Single Simulation Run; Figure 3-2 and 3-4: 10,000 Simulation Runs) 
Chen, Taylor and Unsal

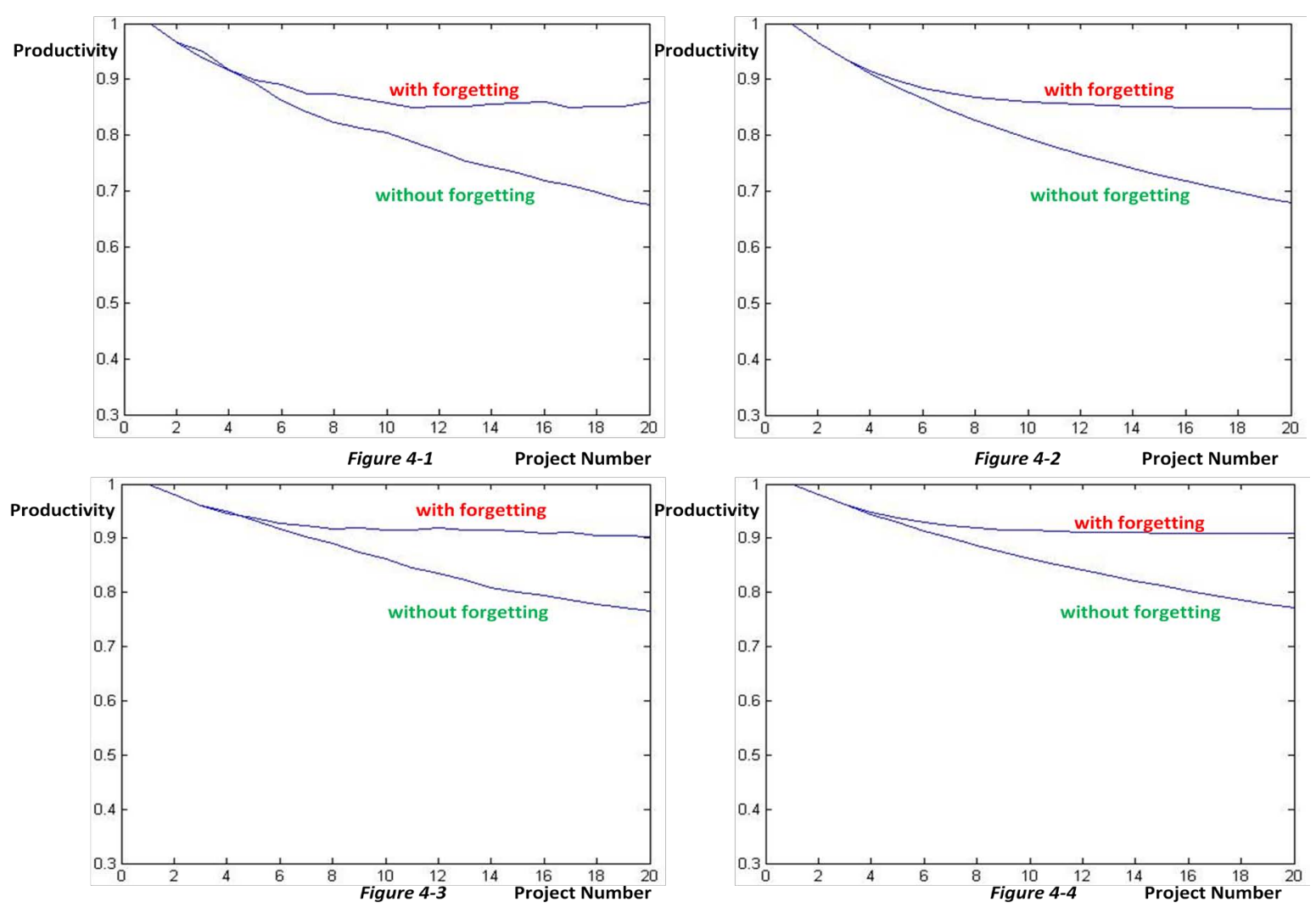

Figure 4: Comparisons of Adaptation Performance With and Without Forgetting with Varying Relational Stability (Figure 41 and 4-3: Single Simulation Run; Figure 4-2 and 4-4: 10,000 Simulation Runs)

Table 2: Comparison of Productivity at the $20^{\text {th }}$ Project (10,000 Simulation Runs)

\begin{tabular}{|c|c|c|c|c|}
\hline \multirow{2}{*}{ \# firms per role } & \multicolumn{2}{|c|}{ Productivity } & \multirow{2}{*}{$\begin{array}{l}\text { Productivity } \\
\text { Reduction* }\end{array}$} & \multirow{2}{*}{$\underset{\text { (r) }}{\text { Reduction Ratio** }}$} \\
\hline & With forgetting & Without forgetting & & \\
\hline 1 firm per role & 0.2838 & 0.2838 & 0.0000 & - \\
\hline 2 firms per role & 0.6826 & 0.5356 & 0.1344 & $24.54 \%$ \\
\hline 3 firms per role & 0.8349 & 0.6782 & 0.1571 & $22.84 \%$ \\
\hline 4 firms per role & 0.9014 & 0.7714 & 0.1300 & $16.94 \%$ \\
\hline 5 firms per role & 0.9349 & 0.8317 & 0.1031 & $12.52 \%$ \\
\hline 6 firms per role & 0.9566 & 0.8714 & 0.0852 & $9.51 \%$ \\
\hline
\end{tabular}

*Productivity Reduction $=$ Productivity with forgetting - Productivity without forgetting

**Reduction Ratio (r) = Productivity Reduction / Productivity without forgetting

From the above table, in the situation where there is only 1 firm per role, there is no forgetting period caused by relational instability. This is due to the fact that on each project the same firm would participate. Irrespective of whether we examine productivity with forgetting or without forgetting, the productivity is reduced by the unstable relationship. Forgetting intensifies this trend. The reduction ratio in the table above indicates that the impact of forgetting is reduced with increasing instability. This may be related to the fact that there is an upper bound on the amount that productivity can be worsened. In other words, a firm or firm network should always be able to perform at least as well as it did in the first 


\section{Chen, Taylor and Unsal}

project. Nevertheless, the simulation demonstrates that forgetting has a negative impact on the adaptation rate of relationally unstable project networks. Hence we put forward the following proposition:

Proposition 1 As relational instability among firms in a network increases, the impact of forgetting on adaptation performance diminishes.

\subsection{The Impact of Task Interdependence on Learning Dynamics with Forgetting}

In order to identify the effect of task interdependence on the adaptation performance of a project network when a forgetting function is included, we compare the following range of task interdependence rates in Table 3:

Table 3: Learning Dynamics Simulation with Varying Task Interdependence (10,000 Simulation Runs)

\begin{tabular}{|c|c|c|c|c|c|c|c|}
\hline $\begin{array}{l}\text { \# Firms } \\
\text { per Role }\end{array}$ & $\begin{array}{l}\text { Degree of Task } \\
\text { Interdependence }\end{array}$ & $\begin{array}{c}\text { Learning } \\
\text { Rate }\end{array}$ & $\begin{array}{l}\text { \# Projects } \\
\text { Simulated }\end{array}$ & $\begin{array}{c}\text { Project } \\
\text { Duration } \\
\text { (days) }\end{array}$ & $\begin{array}{c}\text { Total } \\
\text { Forgetting } \\
\text { Time (days) }\end{array}$ & $\begin{array}{l}\mathrm{r} \text { at the } \\
20 \text { th } \\
\text { project }\end{array}$ & $\begin{array}{l}\text { Figure } \\
\text { Number }\end{array}$ \\
\hline \multirow{5}{*}{$\begin{array}{l}2 \text { firms } \\
\text { per role }\end{array}$} & 0.1 & \multirow{20}{*}{0.8} & \multirow{20}{*}{20} & \multirow{20}{*}{100} & \multirow{20}{*}{1,000} & $36.80 \%$ & \multirow{5}{*}{ Figure 5-1 } \\
\hline & 0.3 & & & & & $28.27 \%$ & \\
\hline & 0.5 & & & & & $24.54 \%$ & \\
\hline & 0.7 & & & & & $22.52 \%$ & \\
\hline & 0.9 & & & & & $21.26 \%$ & \\
\hline \multirow{5}{*}{$\begin{array}{l}3 \text { firms } \\
\text { per role }\end{array}$} & 0.1 & & & & & $34.80 \%$ & \multirow{5}{*}{ Figure $5-2$} \\
\hline & 0.3 & & & & & $26.02 \%$ & \\
\hline & 0.5 & & & & & $22.84 \%$ & \\
\hline & 0.7 & & & & & $21.16 \%$ & \\
\hline & 0.9 & & & & & $20.15 \%$ & \\
\hline \multirow{5}{*}{$\begin{array}{l}4 \text { firms } \\
\text { per role }\end{array}$} & 0.1 & & & & & $28.08 \%$ & \multirow{5}{*}{ Figure 5-3 } \\
\hline & 0.3 & & & & & $19.65 \%$ & \\
\hline & 0.5 & & & & & $16.94 \%$ & \\
\hline & 0.7 & & & & & $15.61 \%$ & \\
\hline & 0.9 & & & & & $14.81 \%$ & \\
\hline \multirow{5}{*}{$\begin{array}{l}5 \text { firms } \\
\text { per role }\end{array}$} & 0.1 & & & & & $22.36 \%$ & \multirow{5}{*}{ Figure $5-4$} \\
\hline & 0.3 & & & & & $14.80 \%$ & \\
\hline & 0.5 & & & & & $12.52 \%$ & \\
\hline & 0.7 & & & & & $11.43 \%$ & \\
\hline & 0.9 & & & & & $10.78 \%$ & \\
\hline
\end{tabular}

Where;

Pw is the productivity of Project Network Learning Model with forgetting;

Po is the productivity of Project Network Learning Model without forgetting;

$r$ is the Reduction Ratio of Project Network Learning 

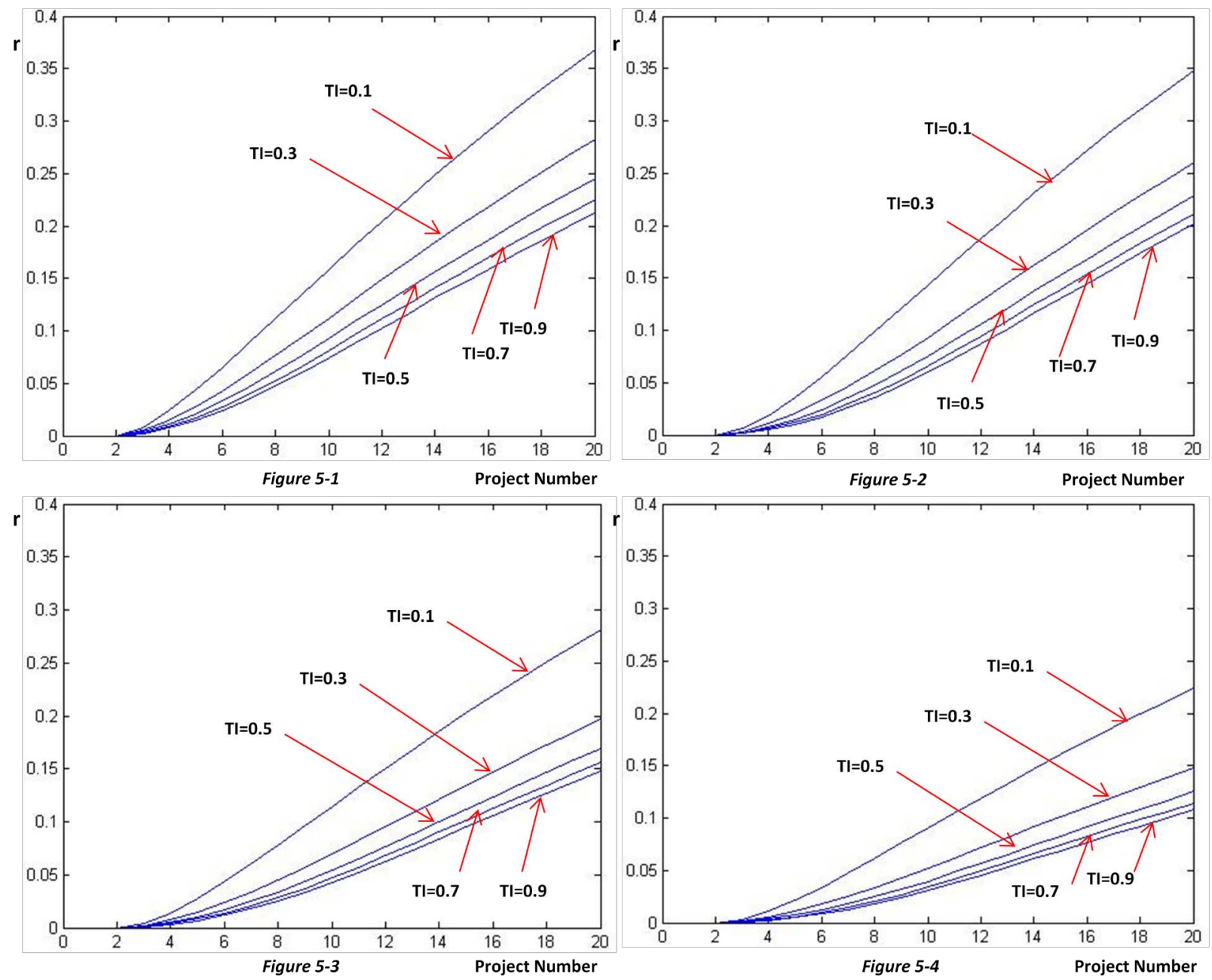

Figure 5: Cumulative Differences between Varying Levels of Task Interdependence (Figure 5-1 $=2$ firms per role, Figure 5-2 $=3$ firms per role, Figure 5-3 = 4 firms per role, Figure 5-4 = 5 firms per role)

Table 3 and Figure 5 demonstrate that as task interdependence increases in a relatively relationally stable network that productivity is impacted negatively. For example, in 2 firms per role networks, when task interdependence is 0.1 the reduction ratio is $36.8 \%$ and when task interdependence equals 0.9 the reduction ratio will decline to $21.56 \%$. The difference between productivity with forgetting and without forgetting is diminishing but the effect on productivity is still negative. When relational instability increases, we observe that varying degrees of task interdependence negatively impacts productivity but again the effect diminishes with increasing relational instability. From Table 3 we can observe the reduction ratio of 0.5 task interdependence will decrease with an increasing number of firms per role in project network. The inclusion of forgetting in project network adaptation performance modeling appears to have a synergistic negative effect when relational instability increases are coupled with increases in the degree of task interdependence.

Proposition 2 Relational instability, task interdependence and learning decay have a synergistic and negative effect on adaptation performance.

\section{MODEL VALIDATION AND LIMITATIONS}

The purpose of this simulation is to implement project network learning theory by using several controllable input parameters. One incomplete part of existing theory is the impact of forgetting caused by unstable interorganizational relationships. In order to achieve the goal, realism and purpose, suggested by Burton and Obel (1995), we built our simulation on the project network dynamics learning model developed by Taylor and colleagues (Taylor et al. in press), which in turn is based on established learning curve theory (Wright 1936). We apply an established model for learning and 
forgetting (Jaber and Bonney 1996), to examine the effect it may have on relationally unstable project networks. Hence, the internal validity of the model is strengthened by the fact that it is rooted in established and proven theoretical models.

However, this model also is based on several assumptions and hence the findings are limited. First, the model does not allow simultaneous project execution to take place. If multiple projects are executed at the same time, the learning gaps may be shortened and the impact of forgetting lessened. Second, the learning rate we used is uniform in every firm; however, in practice each firm has its own distinct learning rate determined by its working environment, crew experience, equipment and leadership. A third limitation is the fact that we modeled the project networks as a closed system. In reality new entrants would join networks and some firms would defect from those networks influencing the adaptation performance outcomes. Lastly, the network and each organization share the same learning and forgetting function. It is not clear if interorganizational learning and forgetting have lower or higher learning or forgetting rates.

\section{CONCLUSION}

Researchers have argued that the learning that takes place in interorganizational networks has not been sufficiently characterized (Mowery et al. 1996). In this paper we extend previous computational simulation modeling research on project network learning dynamics. We integrate a model of forgetting to account for learning decay between learning events in order to understand the impact of relational instability on project network productivity over time. We demonstrate that the significant gaps in time that can result from relationally unstable network relationships have a synergistic and negative impact on the adaptation performance of project networks when coupled with changes in relational stability and task interdependence. We find that as relationship instability and task interdependence increases, the impact of forgetting diminishes when compared to adaptation performance without modeling forgetting. We conclude that relational instability, task interdependence and learning decay are three key factors that impact project network learning. In identifying these relationships, our research contributes to a fuller understanding of learning in project networks. Future research should examine the relative contribution of each key factor on adaptation performance. This could be executed with a combination of agent-based modeling and multi-variant regression research approaches.

\section{REFERENCES}

Appleyard, M. 1996. How does knowledge flow? Interfirm Patterns in the Semiconductor Industry. Strategic Management Journal, 17: 137-154

Bailey, C. 1989. Forgetting and the Learning Curve: A Laboratory Study. Management Science 35(3): 340-352.

Burton, R., and B. Obel. 1995. The Validity of Computational Models in Organization Science: From Model Realism to Purpose of the Model. Computational and Mathematical Organization Theory 1(1): 57-71.

Carlson, J. G., and R. G. Rowe. 1976. How much does forgetting cost? Industrial Engineering 8(9): 40-47.

Carron, A. V. 1971. Laboratory Experiments in Motor Learning, Englewood Cliffs: Prentice-Hall, Inc.

Christiaansen R.E., Prose Memory: Forgetting Rates for Memory Codes, Journal of Experimental Psychology: Human Learning and Memory 6(5): 611-619.

Coase, R. 1937. The nature of the firm. Economica 4(16): 386-405.

Demian, P., and R. Fruchter. 2006. Methodology for Usability Evaluation of Corporate Memory Design reuse systems. Journal of Computing in Civil Engineering 20(6): 377-389.

Eccles, R. 1981. The quasifirm in the construction industry. Journal of Economic Behavior and Organization 2(4): 335-357.

Fruchter, R. 1999. A/E/C teamwork: collaborative design and learning space. Journal of Computing in Civil Engineering, 13(4): 262-269.

Gann, D., and A. Salter. 2000. Innovation in project-based, service-enhanced firms: The construction of complex products and systems. Research Policy 29: 955-972

Hijazi, A., S. AbouRizk, and D. Halpin. 1992. Modeling and simulating learning development in construction. Journal of Construction Engineering and Management 118(4): 685-700.

Hovland, C. I. 1951. Human learning and retention. Handbook of experimental psychology In Social Science. 7th ed. New York: Wiley.

Hussein, K., and F. Pena-Mora. 1999. Frameworks for interaction support in distributed learning environments. Journal of Computing in Civil Engineering 13(4): 291-302.

Ibrahim, R., and M. Nissen. 2003. Emerging technology to model dynamic knowledge creation and flow among construction industry stakeholders during the critical feasibility-entitlements phase. In Proceedings Joint Symposium on IT in Civil Engineering, ASCE, Reston, VA.

Jaber, M., and M. Bonney. 1996. Production breaks and the learning curve: The Forgetting phenomenon. Applied Mathematical Modeling 20(2): 162-169. 
Jaber, M., and M. Bonney. 1997. A comparative study of learning curves with forgetting. Applied Mathematical Modeling 21(8): 524-531.

Lutz, J., D. Halpin, and J. Wilson. 1994. Simulation of learning development in repetitive construction. Journal of Construction Engineering and Management 120(4): 753-777.

Mosheiov, G., and B. Sidney. 2003. Scheduling with general job-dependent learning curves. European Journal of Operational Research 147(3): 665-670.

Mowery, D., J. Oxley, and B. Silverman. 1996. Strategic alliances and interfirm knowledge transfer. Strategic Management Journal 17: 77-91.

Oglesby, C., H. Parker, and G. Howell. 1989. Productivity Improvement in Construction, New York: McGraw Hill.

Powell, W.1998. Learning from collaboration: Knowledge and networks in biotechnology and pharmaceutical industries. California Management Review 40(3): 228-240.

Rao, R.D., and L. Argote. 2006, Organizational learning and forgetting: The effects of turnover and structure. European Management Review 3(2): 77-85.

Soibelman, L., and H. Kim. 2002. Data Preparation Process for Construction Knowledge Generation through Knowledge Discovery in Databases. Journal of Computing in Civil Engineering 16(1): 39-48.

Taylor, J., and R. Levitt. 2004. Understanding and Managing Systemic Innovation in Project-based Industries. In Innovations: Project Management Research, ed. D. Slevin, D. Cleland and J. Pinto, 83-99. Newton Square: Project Management Institute.

Taylor, J., and R. Levitt. 2007. Innovation alignment and project network dynamics: An integrative model for change. Project Management Journal 38(3): 22-35.

Taylor, J., R. Levitt, and A. Villarroel, In Press. Simulating Learning Dynamics in Project Networks, ASCE Journal of Construction Engineering and Management.

Underwood, B. J. 1968. Forgetting, International Encyclopedia of the Social Sciences, 5: 536-542. New York: Macmillan.

Unsal, H., and J. Taylor. 2009. Integrating agent-based simulation with game theory to investigate the hold-up problem in project networks. In Proceedings of the Construction Research Congress, ASCE, Seattle, WA.

Uzzi, B., and J. Gillespie. 2002. Knowledge spillover in corporate financing networks: Embeddedness and firms debt performance. Strategic Management Journal 23(7): 595-618.

Villarroel, A., and J. Taylor. 2006. An agent-based approach to examine the network knowledge advantage in open innovation networks: Firm openness and interorganizational network performance, In Proceedings of Agent 2006 Annual Conference, Chicago, IL.

Wickelgren, W. A. 1981. Human Learning and Memory, Annual Review of Psychology 32: 21-52.

Williamson, O. 1975. Markets and Hierarchies, New York: MacMillan.

Wixted, T. 1991. On the Form of Forgetting, American Psychological Society 2(6): 409-415.

Wright, T. 1936. Learning Curve, Journal of the Aeronautical Sciences. 3: 122-128.

Zucker, L., M. Darby, M. Brewer, and Y. Peng. 1996. Collaboration structure and information dilemmas in biotechnology: Organizational boundaries as trust production. Trust in Organizations, ed. R.Kramer and T. Tyler, 90-113. Thousand Oaks: Sage.

\section{AUTHOR BIOGRAPHIES}

JIAYU CHEN is a Graduate Research Assistant in the Civil Engineering and Engineering Mechanics Department at Columbia University. He conducts simulation research in the Project Network Dynamics Lab on the impact of relational stability and performance decay in project networks. His email is <jc3252@columbia.edu $\rangle$.

JOHN E. TAYLOR is an Assistant Professor of Construction Engineering and Project Management within the Department of Civil Engineering and Engineering Mechanics at Columbia University. He received his Ph.D. from Stanford University in 2006. He is Director of the Project Network Dynamics Lab at Columbia University and his research interests include project organizational network dynamics associated with cross-boundary technology integration, inter-cultural interactions on global projects, and the diffusion of energy efficient practices in building occupant networks. His email is $<j$ t2411ecolumbia.edu>.

HAKAN UNSAL is a Graduate Research Assistant in the Civil Engineering and Engineering Mechanics Department at Columbia University. He conducts simulation research in the Project Network Dynamics Lab on application of game theoretic models to examine opportunistic behavior of bidders in project networks. His email is

$<$ hiu2001@columbia.edu>. 